\title{
Impact of Depression on Food Consumption Frequency among Medical Students of Rawalpindi Medical University, Pakistan
}

Tayyab Mumtaz Khan, Somia Bibi, Samia Tul Rasool, Manahil Jamil, Shahrukh Khan, Hajrah Shafique, Syeda Uroosa Jafri, Huma Ishfaq, Sania Salamat, Umama Fatima Iqbal, Huma Amjad, Madeeha Mumtaz

\section{ABSTRACT}

Depression is very common and multi-problematic disorder, and it can affect almost all aspects of lives of people including the way people eat, sleep, behave and perform. Depression can also lead to increase in consumption of unhealthy foods. This study is set to assess impact of depression on the consumption frequency of various food groups among final-year medical students of Rawalpindi Medical University Pakistan. This may bring new way to improve physical health through application of interventions for mental health. This descriptive cross-sectional study was conducted in December 2019 among final year medical MBBS students of Rawalpindi Medical University Pakistan. Two questionnaires were used for data collection including, Center for Epidemiologic Studies Depression Scale Revised-10 (CESD-R-10) for depression assessment while a self-structured questionnaire which was designed to get information regarding demographic details and food consumption of various food groups (Fresh foods, Sweet foods, Ready to eat foods, Snack foods and Fast Foods). Students who had any physical and mental illness and irregular dietary habits were excluded. From the total of 307 participants of study, 269 participants gave back properly filled questionnaires, therefore, final sample size became 269. Data analysis was accomplished through SPSS v.25.0. Because of non-parametric nature of data different non-parametric statistical tests including Mann-Whitney test, Kruskal-Wallis test and Spearman correlation were applied to evaluate the study variables. A pvalue less than 0.05 was considered statistically significant. Difference in depression was statistically significant, across gender $(p=0.007)$ and boarding status $(\mathrm{p}=\mathbf{0 . 0 0 0})$. Significant differences of depression were also found across intake three frequency levels of $\operatorname{sweet}$ foods $(p=0.000)$, fast foods $(p=0.000)$, snack foods $(p=0.000)$, ready to eat foods $(p=0.000)$ and fruits and vegetables $(p=0.000)$. Spearman correlation coefficient was positive for four foods groups including sweet foods $(0.426$ with $p=0.000)$, fast foods $(0.610$ with $p=0.000)$, snack foods $(0.611$ with $p=0.000)$, ready to eat foods $(0.649$ with $p=0.000)$, while for fruits and vegetables $(-0.640$ with $p=0.000)$ it was negative. Positive values of Spearman correlation coefficient for sweet foods, fast foods, snack foods, and ready to eat foods indicate that, increase in depression leads to increase in consumption of these food groups while, negative value for fruits and vegetables indicates that increase in depression leads to reduction in consumption of this food group. Our study results show that depression leads to change in consumption frequency of various food groups. Increase in depression leads to increase consumption frequency of unhealthy food groups including sweet foods, fast foods, snack foods, ready to eat foods while increase in depression leads to decrease consumption frequency of fruits and vegetables. Therefore, by applying suitable intervention for the alleviation of depression we can improve dietary habits and consequently physical health.

Keywords: Impact, Depression, Food, Consumption, Frequency, Medical Students, Rawalpindi Medical University, Pakistan.
Published Online: November 28, 2020

ISSN: 2593-8339

DOI: $10.24018 /$ ejmed.2020.2.6.578

Tayyab Mumtaz Khan*

Rawalpindi Medical University, Pakistan.

(e-mail: tayyab.mkhan98@gmail.com)

Somia Bibi

Rawalpindi Medical University, Pakistan. Samia Tul Rasool

Rawalpindi Medical University, Pakistan. Manahil Jamil

Rawalpindi Medical University, Pakistan. Shahrukh Khan

University of Veterinary and Animal Sciences, Pakistan.

Hajrah Shafique

University of Veterinary and Animal Sciences, Pakistan.

Syeda Uroosa Jafri

University of Veterinary and Animal Sciences, Pakistan.

Huma Ishfaq

University of Agriculture, Pakistan. Sania Salamat

Pir Mehr Ali Shah, Arid Agriculture University, Pakistan.

Umama Fatima Iqbal

The University of Lahore, Pakistan. Huma Amjad

The University of Lahore, Pakistan.

Madeeha Mumtaz

Lahore College for Women University, Pakistan.

*Corresponding Author

\section{INTRODUCTION}

Depression is a multi-problematic disorder that can cause the impairment of individual, social, and occupational functioning [1]. It is an extremely dominant and widespread problem and it is one of the main global causes of disability among people and is expected to be the leading cause of disease disability by 2040 [2]. Mental disorders have been major factors in causing inconvenience among students of all domains, nevertheless, mental illnesses are more prevalent among students of medical filed [3]-[7]. A study that was conducted in India has also been shown high prevalence of 
depression among medical students in which more than half students were suffering from depression [8]. Depression among the student population is a cause of concern, especially in medical students because they are confronted with a significant number of stressors such as high failure rates in the MBBS examinations, frequent rescheduling of lectures, large workloads, pressures of the clinical environment, long travel times, inadequate accommodations, study conditions, lecturers' attitudes, finances, frequent multiple assessments, parental expectations, and poor relationship with parents [9]-[12]. Depression affects almost every aspect of life. In literature, it has been shown that depression influences the way individual eats, sleeps, and behaves [13]. Furthermore, a study has also indicated that depression brings other psychological issues in lives including stress, burnout, tension, suicidal thoughts, substance abuse and impairment in cognitive functions and these psychological issues can affect the performance of students in academics and other aspects of life [14], [15]. However, it has been shown that medical students can learn to adapt by using various coping strategies like positive thinking, meeting friends, discussing it with their parent or guardian, seeking medical advice, consulting a religious person, consuming food, sleeping, using relaxation techniques, playing music, crafting, outdoor activities, consuming media, drinking or consuming other legal or illicit drugs [12], [16], [17]. From all above, mentioned coping strategies, one is food consumption of specific type and there is growing evidence that food consumption influences our feelings [18]. In literature, it has also been shown that carbohydrate rich meal affects mood, and it seems to alleviate depressive moods [9]. Another study has also suggested that carbohydrates could relieve depression [19]. Serotonin is a neurotransmitter in brain, and it regulates various functions of brain including mood, reward, appetite, memory, anger, and depression. Carbohydrate rich food increases production of serotonin in brain, so, this could be the reason that carbohydrate rich food reduces depression and elevate mood [20]. Moreover, in literature, it has also been shown that depression leads to change in patterns of dietary consumption and consumption of unhealthy food increases while an individual's motivation to engage in healthy dietary habits decreases [20]. Furthermore, We have examined a few mental health-focused papers with food consumption and found that vegetables, fruit, high fiber, meat, fish, low-fat dairy, elevated polyunsaturated fat/saturated fat ratios, and low trans-fat were negatively associated with depression whereas, and sugar-sweetened beverages, fast food, snacks, and sweets were positively associated with depressive symptoms [9], [20]-[23]. If depression leads to unhealthy food consumption, then this mental health disorder will consequently will disturb physical health as well. Although, many research have been conducted among university students across the world to determine the relationship between depression and food consumption [9], [20],[21]. However, we could find only a few number of studies among Pakistani medical student in which this kind of relationship between depression and food consumption has been evaluated. So, this current study was set up to find which groups of food are consumed more frequently with the increase in depression among medical students to plan necessary interventions addressing unhealthy food practices related to depressive symptoms. If the results of study shows consumption of unhealthy food in depressed students, then by applying interventions that can help them to cope with depression, we may able to increase the consumption of healthy food and resultant improvement in physical health along with mental health.

\section{MATERIAL AND METHODS}

\section{A. Study Design and Study Population}

A cross sectional descriptive study was conducted among final year medical students of Rawalpindi Medical University in December 2019. From total of 375 students of final year, only 307 students were enrolled for study according to exclusion and inclusion criteria for this study. Only those, who were willing to participate in the study and had regular dietary intake habits were recruited in study, while those, who had any diagnosed physical and mental illness during study and had not regular dietary intake were excluded because this could affect the depression and food intake assessment and therefore overall results of study could be affected. Data was collected by using two questionnaires. Two questionnaires were given to all enrolled students. Only 269 participants gave back properly filled questionnaires. Hence, the response rate for our study was $87.62 \%$.

\section{B. Assessment Characteristics of Study Population and Food Intake}

Demographic details and food intake for last month were noted through self structured questionnaire. Demographic portion had questions about the age, gender, and boarding status of participants and in dietary intake portion frequencies of particularly food group were assessed. The carbohydrate-rich and energy-rich foods were categorized into five groups: Fresh foods including ,fruits and raw vegetables, Sweet foods, such as desserts, ice cream, candy, or chocolates, Ready-to-eat foods such as instant noodle, frozen, canned or microwave foods, Snack foods items such as potato chips, corn chips and tortilla chips, Fast foods such as pizza, burgers and shawarma. Three frequency levels of particular food intake were obtained including low frequency, moderate frequency and high frequency. These levels were established by knowing the consumption frequency of each group of food per week during last month. Intake of particular group of food once or less than one a week was considered low frequency level, 2-3times a week or 4-6times a week was considered Moderate frequency level and once a day and more one times per day was considered high frequency level of that particular food group. Sweet foods, ready to eat foods, snack foods, and fast foods were considered unhealthy foods, whereas fruits and vegetables were considered as healthy foods.

\section{Assessment of Depression}

While for the assessment of depression symptoms internationally used questionnaire Center for Epidemiologic Studies Depression Scale Revised (CESD-R-10) was used. This scale has been used around the world [24]. It has four versions with 4, 810 and 20 items, nevertheless, version with 
10 items was used in this current study. For self-reported measure of depression this scale is used. Each item could have score could score 0 (rarely or none of time), 1 (some or a little of the time), 2(occasionally or a moderate amount of time), and 3(all of the time). Reverse Scores for item 5 and 8 were used. Individual participant could have score from 0 to 30 with higher scores indicating higher depression. Participants with score of equal to or greater than 10 were considered depressed.

\section{Data Analysis}

A descriptive analysis of the study variables was carried out using SPSS v.25.0. The reliability of questionnaires in our population was checked with calculation of Cronbach alpha value through a pilot study on 50 students. It was 0.75 for CESD-R-10 and 0.78 for Self Structured questionnaire indicating high inter scale reliability. Non-parametric tests were applied because data was not normally distributed. Mann-Whitney test was used to see if depression differ across the gender and boarding status of the students. Kruskal-Wallis analysis of variance test was used to compare the scores of depression across the three frequency levels of each food group. Finally, direction and strength of association between depression and different food groups were assessed through Spearman correlation. A p-value of less than 0.05 was considered statistically significant.

\section{RESULTS}

The study population consisted of $178(66.2 \%)$ females and 91(33.8\%) males. While 120(44.6\%) were boarder students while 149(55.4\%) were non boarder students. Mean age was 22.94 years with standard deviation (SD) of \pm 1.117 . Out of 269 participants 127(47.2\%) were depressed while $142(52.8 \%)$ were undepressed with mean depression score of $9.93(\mathrm{SD} \pm 5.790)$.

Table 1 shows mean score of depression with SD on scale across gender and boarding status along with $\mathrm{p}$ values which show that difference in depression score is statistically significant across gender and boarding status. Depression score was higher among female and boarder students which indicates higher depression among these students while depression score was lower among male and non-boarders indicates lower depression among these students.

Table 2 shows mean score of depression with SD across frequency levels of each food group along with statistically significant difference of depression among three intake frequency levels for all food groups with $p \leq 0.05$. Strength and direction of association between different food groups and depression represented by Spearman's coefficient and significance of strength which is shown by p-values are also given in table. Positive value of Spearman correlation coefficient for sweet foods, fast foods, snack foods, and ready to eat foods indicate that, with increase in depression leads to increase in consumption of these food groups while, negative value for fruits and vegetables indicates that increase in depression leads to reduction in consumption of this food group. Strength of association between depression and various food groups including ready to eat foods, snack foods, fast foods and fruits and vegetable was strong, whereas it was moderate between depression and sweet foods.

Results of this study shows that consumption of unhealthy foods increases with increase in depression while healthy foods consumption decreases with increase in depression.

TABLE 1: DIFFERENCE IN DEPRESSION MEAN SCORE ACROSS GENDER AND BOARDING STATUS ALONG WITH MANN-WHITNEY ANALYSIS.

\begin{tabular}{cccc}
\hline \multirow{2}{*}{ Parameter } & \multicolumn{2}{c}{$\begin{array}{c}\text { Score on } \\
\text { Depression scale }\end{array}$} & $\begin{array}{c}\text { Mann-Whitney } \\
\text { test }\end{array}$ \\
\cline { 3 - 4 } & & Mean \pm SD & p-Value \\
\hline \multirow{2}{*}{ Gender } & Male & $8.46 \pm 4.911$ & \multirow{2}{*}{0.007} \\
Boarding & Female & $10.69 \pm 6.068$ & \\
Status & Boarder & $11.67 \pm 6.262$ & 0 \\
& Non Boarder & $8.54 \pm 4.978$ & 0.000 \\
\hline
\end{tabular}

TABLE 2: DIFFERENCE IN DEPRESSION MEAN SCORE ACROSS THREE INTAKE FREQUENCY LEVEL OF VARIOUS FOOD GROUPS ALONG WITH KRUSKALWALLIS ANALYSIS AND SPEARMAN'S CORRELATION.

\begin{tabular}{|c|c|c|c|c|c|}
\hline \multirow{2}{*}{$\begin{array}{l}\text { Types of } \\
\text { Food }\end{array}$} & \multirow{2}{*}{$\begin{array}{l}\text { Frequency } \\
\text { Levels }\end{array}$} & \multirow{2}{*}{$\begin{array}{l}\text { Depression } \\
\text { Score } \\
\text { Mean } \pm \text { SD }\end{array}$} & \multirow{2}{*}{$\begin{array}{c}\begin{array}{c}\text { Kruskal- } \\
\text { Wallis } \\
\text { test }\end{array} \\
\text { p-Value }\end{array}$} & \multicolumn{2}{|c|}{$\begin{array}{l}\text { Spearman's } \\
\text { Correlation }\end{array}$} \\
\hline & & & & $\begin{array}{c}\text { Correlation } \\
\text { Coefficient } \\
\text { (r) }\end{array}$ & $\begin{array}{c}\mathrm{p}- \\
\text { Value }\end{array}$ \\
\hline $\begin{array}{l}\text { Sweet } \\
\text { Food }\end{array}$ & $\begin{array}{c}\text { High } \\
\text { Moderate } \\
\text { Low } \\
\text { High }\end{array}$ & $\begin{array}{c}14.68 \pm 5.811 \\
9.36 \pm 5.097 \\
7.62 \pm 4.679 \\
14.29 \pm 4.805\end{array}$ & 0.000 & 0.426 & 0.000 \\
\hline Fast Food & $\begin{array}{l}\text { Moderate } \\
\text { Low }\end{array}$ & $\begin{array}{l}9.19 \pm 5.339 \\
6.58 \pm 4.170\end{array}$ & 0.000 & 0.610 & 0.000 \\
\hline $\begin{array}{l}\text { Snack } \\
\text { Food }\end{array}$ & $\begin{array}{l}\text { High } \\
\text { Moderate } \\
\text { Low }\end{array}$ & $\begin{array}{c}15.86 \pm 4.953 \\
10.55 \pm 4.542 \\
6.69 \pm 4.411\end{array}$ & 0.000 & 0.611 & 0.000 \\
\hline $\begin{array}{l}\text { Ready to } \\
\text { eat Food }\end{array}$ & $\begin{array}{l}\text { High } \\
\text { Moderate } \\
\text { Low }\end{array}$ & $\begin{array}{c}16.02 \pm 5.299 \\
10.54 \pm 4.012 \\
6.42 \pm 3.961\end{array}$ & 0.000 & 0.649 & 0.000 \\
\hline $\begin{array}{l}\text { Fruits and } \\
\text { raw } \\
\text { Vegetables }\end{array}$ & $\begin{array}{l}\text { High } \\
\text { Moderate } \\
\text { Low }\end{array}$ & $\begin{array}{c}5.58 \pm 3.460 \\
8.32 \pm 4.162 \\
13.91 \pm 5.298\end{array}$ & 0.000 & -0.640 & 0.000 \\
\hline
\end{tabular}

\section{DISCUSSION}

The results of our study shows impact of depression on the food selection among medical students of Rawalpindi Medical University, Pakistan. Our current study also provides valuable information regarding the trends of depression among medical students based on their gender and boarding status. In beginning of data analysis, in our study we noted overall high prevalence of depression among medical students of Rawalpindi Medical University, Pakistan. In literature, high prevalence of depression has also been observed in a study that was conducted in India [8]. In next step, we observed variation of depression score among medical students based on their gender and boarding status. We found that depression prevalence and depression score on Center for Epidemiological Studies Depression Scale Revised-10 was higher among female students in contrast with male students. This difference of depression across gender was statistically significant with $\mathrm{p}$ value of 0.007 . This difference and its significance were assessed by MannWhitney test. Higher prevalence of depression among female students has also been noticed in a cross-sectional study that was conducted in Karachi, Pakistan [25]. Because women are known to have poor coping plans, more moaning and dubious nature even about trivial and daily life issues, so, all of these qualities could be the cause of higher prevalence of 
depression among female students. Difference in depression score among medical students on the basis of their boarding status was also observed. Depression score was higher among boarder students which means that they had higher level of depression or they had more symptoms of depression relative to non boarder students. Difference of depression across boarder status was also significant statistically as across the gender with $\mathrm{p}$ value of 0.000 . this was also assessed with help of Mann-Whitney test. A study that was conducted in Kenya, has also showed the higher level of depression among students that live in boarding houses in comparison with students live in own homes [26]. Reasons can be various including lack of close friends, lack of family members, presence of strange and new territory, homesickness and all these reasons lead to poor mental health like higher level of depression among students live in boarding houses. On further analysis of data, we noted the difference in score of depression across three intake levels of all five included food groups (Sweet Foods, Fast Foods, Snack Foods, Ready to eat foods, and fruits and vegetables). Difference in depression score was significant across three intake levels of all food groups, therefore we can say that depression has significant impact on the selection food groups among medical students. In a study that was conducted among students of China had also noted statistically significant difference of depression score across intake levels of food groups including ready to eat foods, snack foods, fast foods, and fruits and vegetables, however, statistically nonsignificant difference was only noticed across intake level of sweet foods [20]. At end of data analysis, we applied Spearman correlation to assess the strength and direction of association between depression and various food groups. Association between depression and all food groups was statistically significant with $\mathrm{p}$ value of less than 0.000. Spearman Correlation was 0.649 with p-value of 0.000 for ready to eat foods and depression, for snack foods and depression it was 0.611 with p value 0.000 , for fast foods and depression it was 0.610 with $p$ value of 0.000 , for sweet foods and depression it was 0.426 with $p$ value of 0.000 , and for Fruits and Vegetables it was -0.640 with $p$ value of 0.000 . Association was strong and positive for ready to eat foods, snack foods and fast foods while it was moderate and positive for sweet foods, whereas it was strong and negative for fruits and vegetables. Strong and positive association between various food groups means that with increase of depression, consumption of these food groups increases to extreme extent, while moderate and positive association means that consumption increases with depression, however, this increase in consumption would be moderate in extent. Whereas the strong and negative association between depression and various food groups means that with the increase in depression, consumption of these food groups decreases to great extent. Similar findings have been observed in different researches that were conducted in United Kingdom and China for four food groups including ready to eat foods, snack foods, fast foods and fruits and vegetables, however, in Chinese study impact of depression on sweet foods consumption was not significant. [9], [20]. So, at this point we can say, that with increase in depression, students preference for food changes and they consume more unhealthy foods as compare to healthy foods which can leads to decline in physical health od students including obesity, diabetes and cardiovascular diseases. In literature various reasons have given that why students prefer unhealthy foods over healthy foods when they get depressed including immediate and convenient availability, high calories, and easy digestibility [19],[21],[27]. Another one important reason is that included unhealthy foods in current study are carbohydrate rich and one study has concluded that carbohydrate rich food leads to increase production of serotonin which consequently, causes improvement in mood of depressed people [19], [20]. No matter what is the reason of increase consumption of unhealthy foods, it would always lead to deterioration in physical health. So, we should put efforts to decrease depression among students and subsequently, that could lead to increase in healthy foods consumption and decrease in unhealthy food consumption. This study is first study, in which impact of depression on food selection has been evaluated among final year medical students of Rawalpindi Medical University Rawalpindi, Pakistan. This makes our study unique in its approach. We have noticed in this this study, that increase in depression leads to increase consumption of unhealthy foods among medical students and vice versa. Therefore, at end of this study, we suggest that universities should organize workshops for the students that provide information regarding the suitable coping plans which students could use to get rid of depression. After making students aware about coping strategies and by employing different appropriate measures that could help students in improvement in mood of depressed students, we may also become successful in changing dietary pattern of students and increase in consumption of healthy foods and subsequently, boost in physical health together with mental health.

\section{CONCLUSION}

Results of our study indicates higher depression among female and boarder students as compare to male and nonboarder students and this difference is statistically significant. Depression leads to change in dietary pattern, consumption of unhealthy food groups including sweet foods, fast foods, snack foods, ready to eat foods increases with the increase in depression while consumption of healthy food group including fruits and vegetables decreases with the increase in depression. By implementation of suitable measures for the reduction of depression we can increase the consumption healthy food consequently improvement in physical health along with mental health.

\section{REFERENCES}

[1] Khan UH, Asif E, Hassan SA, Rahmat R, Zohra EH. Prevalence of Nutritional Anaemia with Association of (BMI) 3 Body Mass Index among Karachi University students, Pakistan 4. Journal of the Pakistan Medical Association. 2020 Oct 19:1-0.

[2] Reddy MS. Depression-The Global Crisis.

[3] Mikolajczyk RT, Maxwell AE, Naydenova V, Meier S, El Ansari W Depressive symptoms and perceived burdens related to being a student: Survey in three European countries. Clinical Practice and Epidemiology in Mental Health. 2008 Dec 1;4(1):19. 
[4] Mikolajczyk RT, Maxwell AE, El Ansari W, Naydenova V, Stock C, Ilieva S, Dudziak U, Nagyova I. Prevalence of depressive symptoms in university students from Germany, Denmark, Poland and Bulgaria. Social psychiatry and psychiatric epidemiology. 2008 Feb 1;43(2):105-12.

[5] Tavolacci MP, Ladner J, Grigioni S, Richard L, Villet H, Dechelotte P. Prevalence and association of perceived stress, substance use and behavioral addictions: a cross-sectional study among university students in France, 2009-2011. BMC public health. 2013 Dec 1;13(1):724.

[6] Behere SP, Yadav R, Behere PB. A comparative study of stress among students of medicine, engineering, and nursing. Indian journal of psychological medicine. 2011 Jul;33(2):145.

[7] Dahlin M, Joneborg N, Runeson B. Stress and depression among medical students: A cross-sectional study. Medical education. 2005 Jun;39(6):594-604.

[8] Iqbal S, Gupta S, Venkatarao E. Stress, anxiety \& depression among medical undergraduate students \& their socio-demographic correlates. The Indian journal of medical research. 2015 Mar;141(3):354.

[9] El Ansari W, Adetunji H, Oskrochi R. Food and mental health: relationship between food and perceived stress and depressive symptoms among university students in the United Kingdom. Central European journal of public health. 2014 Jun 1;22(2):90-7.

[10] Bhujade VM. Depression, anxiety and academic stress among college students: A brief review. Indian Journal of Health \& Wellbeing. 2017 Jul 1;8(7).

[11] Kunwar D, Risal A, Koirala S. Study of depression, anxiety and stress among the medical students in two medical colleges of Nepal. Kathmandu Univ Med J. 2016 Jan;53(1):22-6.

[12] Nwobi EA, Ekwueme OC, Ezeoke UE. Mental depression and coping strategies among medical students of University of Nigeria, Enugu campus. International Journal of Medicine and Health Development. 2009 Jan; 14:42-8.

[13] Ali A, Rao MH, Ali S, Ahmed T, Safi M, Malik A, Husan B. Prevalence of anxiety and depression and their associated risk factors among engineering students in Karachi, Pakistan. Int J Emerg Technol Adv Eng. 2014;4:52-55.

[14] Moir F, Yielder J, Sanson J, Chen Y. Depression in medical students: current insights. Advances in medical education and practice. 2018;9:323.

[15] Turner DP, Thompson ME, Brunner Huber LR, Arif AA. Depressive symptoms and academic performance of North Carolina college students. North Carolina medical journal. 2012;73(3):169.

[16] Singh M. Mood, food, and obesity. Frontiers in psychology. 2014 Sep 1;5:925.

[17] Steiner-Hofbauer V, Holzinger A. How to cope with the challenges of medical education? Stress, depression, and coping in undergraduate medical students. Academic Psychiatry. 2020 Feb 20:1-8.

[18] Meyer BJ, Kolanu N, Griffiths DA, Grounds B, Howe PR, Kreis IA. Food groups and fatty acids associated with self-reported depression: an analysis from the Australian National Nutrition and Health Surveys. Nutrition. 2013 Jul 1;29(7-8):1042-7.

[19] Wurtman RJ, Wurtman JJ. Carbohydrates and depression. Scientific American. 1989 Jan 1;260(1):68-75.

[20] Liu C, Xie B, Chou CP, Koprowski C, Zhou D, Palmer P, Sun P, Guo Q, Duan L, Sun X, Johnson CA. Perceived stress, depression and food consumption frequency in the college students of China Seven Cities. Physiology \& behavior. 2007 Nov 23;92(4):748-54.

[21] Mikolajczyk RT, El Ansari W, Maxwell AE. Food consumption frequency and perceived stress and depressive symptoms among students in three European countries. Nutrition journal. 2009 Dec $1 ; 8(1): 31$.

[22] Akbaraly TN, Sabia S, Shipley MJ, Batty GD, Kivimaki M. Adherence to healthy dietary guidelines and future depressive symptoms: evidence for sex differentials in the Whitehall II study. The American journal of clinical nutrition. 2013 Feb 1;97(2):419-27.

[23] Rius-Ottenheim N, Kromhout D, Sijtsma FP, Geleijnse JM, Giltay EJ. Dietary patterns and mental health after myocardial infarction. Plos one. 2017 Oct 16;12(10):e0186368.

[24] Kehnt LN. Perceived Child Regard, Parenting Stress, and Depressive Symptoms of Nonresidential and Residential Stepmothers (Doctoral dissertation, Walden University).

[25] Ghayas S, Shamim S, Anjum F, Hussain M. Prevalence and severity of depression among undergraduate students in Karachi, Pakistan: A cross sectional study. Tropical Journal of Pharmaceutical Research 2014 Dec 10;13(10):1733-8.
[26] Khasakhala LI, Ndetei DM, Mutiso V, Mbwayo AW, Mathai M. The prevalence of depressive symptoms among adolescents in Nairobi public secondary schools: association with perceived maladaptive parental behaviour. African journal of psychiatry. 2012;15(2):106-13

[27] Oliver G, Wardle J, Gibson EL. Stress and food choice: a laboratory study. Psychosomatic medicine. 2000 Nov 1;62(6):853-65.

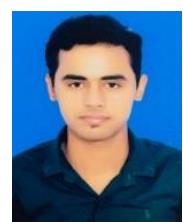

Tayyab Mumtaz Khan

Place and date of birth: Lahore, Pakistan 23-3-1996.

Educational background: Final year MBBS, Rawalpindi

Medical University Rawalpindi, Pakistan. 